\title{
Characterizing the molecular and metabolic mechanisms of insecticide resistance in Anopheles gambiae in Faranah, Guinea
}

Caleb Stica ${ }^{1}$, Claire L. Jeffries ${ }^{1}$, Seth R. Irish ${ }^{2,3}$, Yaya Barry ${ }^{4}$, Denka Camara ${ }^{4}$, Ismael Yansane ${ }^{5}$, Mojca Kristan, Thomas Walker ${ }^{1}$ and Louisa A. Messenger ${ }^{1,2,6^{*}}$ (D)

\begin{abstract}
Background: In recent years, the scale-up of long-lasting insecticidal nets (LLINs) and indoor residual spraying (IRS) has greatly reduced malaria transmission. However, malaria remains a global public health concern with the majority of the disease burden in sub-Saharan Africa. Insecticide resistance is a growing problem among Anopheles vector populations, with potential implications for the continued effectiveness of available control interventions. Improved understanding of current resistance levels and underlying mechanisms is essential to design appropriate management strategies and to mitigate future selection for resistance.
\end{abstract}

Methods: Anopheles gambiae sensu lato mosquitoes were collected from three villages in Faranah Prefecture, Guinea and their levels of susceptibility to seven insecticides were measured using CDC resistance intensity bioassays. Synergist assays with piperonyl butoxide (PBO) were also undertaken to assess the role of elevated mixed-function oxidases in resistance. Five hundred and sixty-three mosquitoes underwent molecular characterization of vector species, presence of target site mutations (L1014F kdr, N1575Y and G119S Ace-1), Plasmodium falciparum infection, and relative expression of three metabolic genes (CYP6M2, CYP6P3 and GSTD3).

Results: In Faranah, resistance to permethrin and deltamethrin was observed, as well as possible resistance to bendiocarb. All assayed vector populations were fully susceptible to al pha-cypermethrin, pirimiphos-methyl, clothianidin and chlorfenapyr. Plasmodium falciparum infection was detected in 7.3\% (37/508) of mosquitoes tested. The L1014F $k d r$ mutation was found in $100 \%$ of a sub-sample of 60 mosquitoes, supporting its fixation in the region. The N1575Y mutation was identified in 20\% (113/561) of individuals, with ongoing selection evidenced by significant deviations from Hardy-Weinberg equilibrium. The G119S Ace-1 mutation was detected in 62.1\% (18/29) of mosquitoes tested and was highly predictive of bendiocarb bioassay survival. The metabolic resistance genes, CYP6M2, CYP6P3 and GSTD3, were found to be overexpressed in wild resistant and susceptible An. gambiae sensu stricto populations, compared to a susceptible G3 colony. Furthermore, CYP6P3 was significantly overexpressed in bendiocarb survivors, implicating its potential role in carbamate resistance in Faranah.

Conclusions: Identification of intense resistance to permethrin and deltamethrin in Faranah, is of concern, as the Guinea National Malaria Control Programme (NMCP) relies exclusively on the distribution of pyrethroid-treated LLINs for vector control. Study findings will be used to guide current and future control strategies in the region.

Keywords: Insecticide resistance, Anopheles gambiae, Guinea, L1014F kdr, N1575Y, G119S Ace-1, Metabolic resistance, CYP6M2, CYP6P3, GSTD3

\footnotetext{
*Correspondence: louisa.messenger@lshtm.ac.uk

1 Department of Disease Control, Faculty of Infectious Tropical Diseases,

London School of Hygiene and Tropical Medicine, London, UK

Full list of author information is available at the end of the article
} 


\section{Background}

Despite impressive progress made towards the control and elimination of malaria, this disease remains the leading cause of morbidity and mortality in the tropics, where it is estimated to have resulted in the deaths of approximately 435,000 individuals in 2017 [1]. Between 2010 and 2017, global malaria incidence has fallen by approximately $18 \%$ globally (72 to 59 cases per 1000 at risk) and by $20 \%$ in the World Health Organization African region [1], which still bears the greatest disease burden [2]. Malaria deaths have been decreasing annually, largely due to the scale-up of long-lasting insecticidal nets (LLINs) [3] and implementation of indoor residual spraying (IRS) [2]. However, progress has stalled in some areas, with an increase of 2 million cases from 2016 to 2017 [1].

Long-term intensive insecticide use to control agricultural pests and disease vectors has resulted in the selection of resistance in many insect species [4]. The widespread use of dichlorodiphenyltrichloroethane (DDT) in the 1950-1960s, followed by the recent increase in distribution of LLINs impregnated with pyrethroids, and the broad use of the same insecticides in the agricultural industry has led to the development of resistance in mosquito populations worldwide [5]. This resistance poses a major threat to malaria control [4], where vector control is reliant primarily on insecticide-based interventions [6]. Of the 80 malaria-endemic countries for which data are available from 2010 onwards, 68 countries detected decreased susceptibility to at least one insecticide among vector populations, with 57 countries reporting resistance to two or more chemical classes [1].

In Guinea, malaria remains one of the most significant diseases of public health importance, with $92 \%$ of infections caused by Plasmodium falciparum [7]. The national malaria prevalence is approximately $15 \%$, reaching up to 25\% in Faranah Prefecture [8]. Guinea's tropical climate allows for year-round malaria transmission, with peak transmission from July through to October in most areas. The Guinean national vector control strategy focuses almost exclusively on the distribution of LLINs, with IRS occurring in only $1.7 \%$ of households, primarily those of workers engaged in mining operations [9]. The United States President's Malaria Initiative (PMI) estimates that intervention coverage remains low, with only $48 \%$ of households owning at least one insecticide-treated net (ITN) per every two members [9]. Given the reliance on LLINs for malaria control, the detection of nationwide pyrethroid resistance is of concern [10]. In order to safeguard malaria control efforts in the country, current insecticide resistance levels and underlying mechanisms were characterized among vector populations, to design appropriate management strategies and mitigate future selection for resistance.

\section{Methods}

\section{Study sites and mosquito collections}

Human landing catches (HLCs) were conducted at three sites in Faranah Prefecture (Fig. 1). The villages of Balayani (10.1325, - 10.7443), Foulaya (10.144633, - 10.749717), and Tindo (9.9612230, - 10.7016560) were selected, due to their high malaria prevalence, and were visited every other day until a sufficient sample size for testing was acquired. Following consent from the household owner, two to three fieldworkers, positioned outside of the house, collected mosquitoes landing and attempting to feed on their exposed legs and feet from 18.00 to 07.00. Mosquitoes were transported back to the insectary in Faranah and provided with $10 \%$ sucrose solution prior to bioassay testing.

Larval collections were also performed in Faranah (10.042423, - 10.740980), at sites selected through active searching and/or known to have been productive in previous years. Larvae and pupae were collected using larval dippers, ladles, buckets, and pans. Collections were then transported back to the insectary in Faranah where they were fed on ground fish food (TetraMin ${ }^{\circledR}$ Tropical Fish Food Flakes). Pupae were removed on a daily basis, placed in plastic cups, and transferred to mosquito cages. Emerging adult mosquitoes were provided 10\% sucrose solution prior to bioassay testing. All mosquito samples were collected between 25th June and 20th July 2018, at the start of the long rainy season.

\section{CDC resistance intensity and synergist bioassays}

Centers for Disease Control and Prevention bottle bioassays were performed using $250 \mathrm{~mL}$ Wheaton bottles with adult female mosquitoes of varying ages caught in HLCs from the three villages (each village was tested separately), or 2-5-day old female mosquitoes raised from larvae in the insectary. Mosquitoes collected using different methods were tested separately in bioassays. Bioassays were performed at the Centre de Santé Marché in Faranah; mosquitoes were held in the insectary for no more than $48 \mathrm{~h}$ prior to testing. Following CDC guidelines, bottles were coated with alpha-cypermethrin (12.5 $\mu \mathrm{g} /$ bottle), deltamethrin $(12.5 \mu \mathrm{g} / \mathrm{bottle})$, permethrin $(21.5 \mu \mathrm{g} /$ bottle $)$, and bendiocarb $(12.5 \mu \mathrm{g} /$ bottle $)$ at $1,2,5$, and 10 times the diagnostic dose, and with pirimiphos-methyl (20 $\mu \mathrm{g} /$ bottle), clothianidin (90 $\mu \mathrm{g} /$ bottle), and chlorfenapyr $(100 \mu \mathrm{g} /$ bottle $)$ at the diagnostic dose. Stock solutions for all insecticides and synergists were prepared using 95-98\% ethanol as a solvent for all, clothianidin also included 58.8 $\mu$ g Mero (Sigma-Aldrich, USA), to circumvent issues previously experienced with bottle coating and insecticide crystallization. Approximately 20-25 mosquitoes were introduced into each assay bottle and mortality was recorded in all bottles at the start 

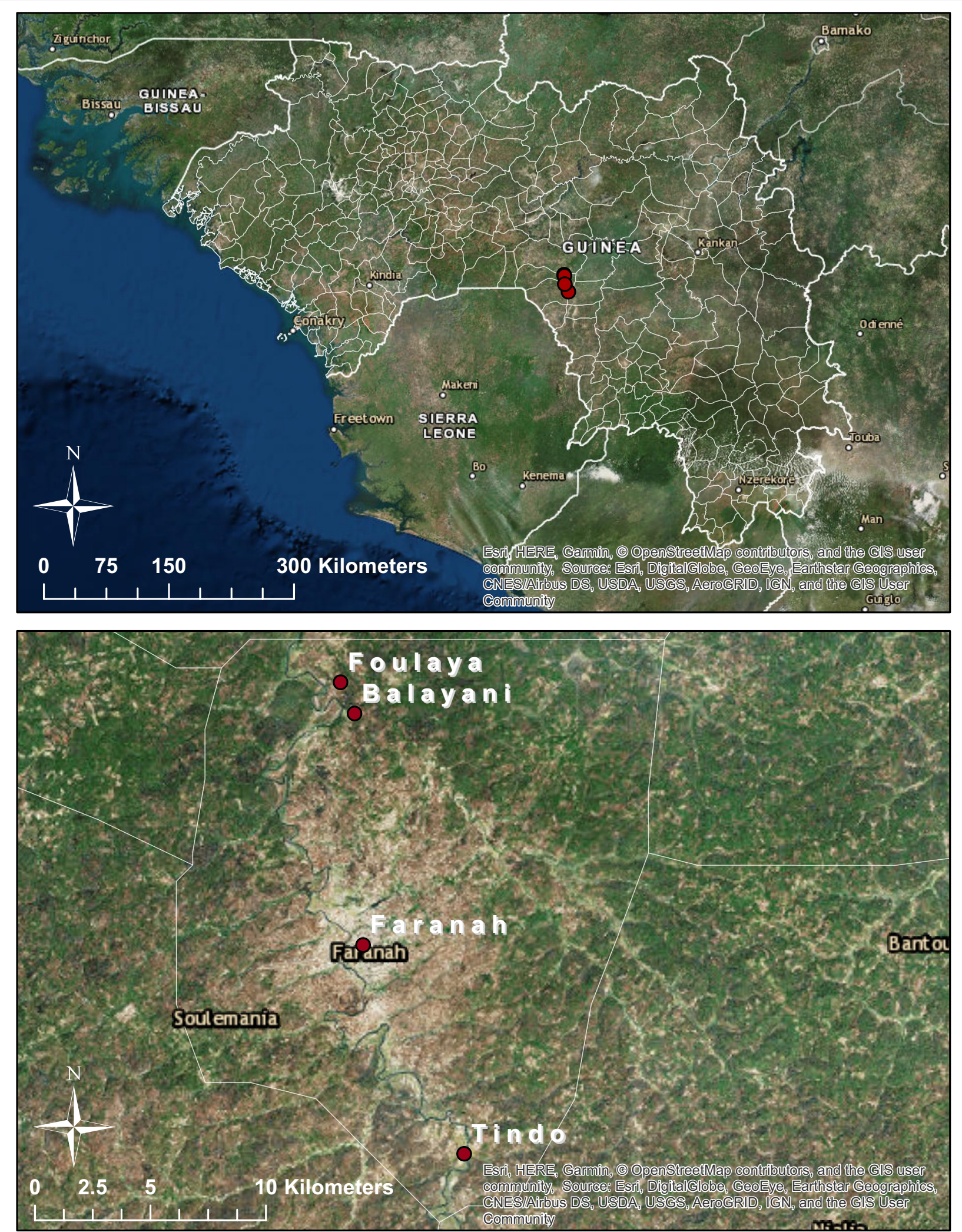

Fig. 1 Map of study sites in Faranah Prefecture, Guinea. Human landing catches (HLCs) were performed in the villages of Balayani, Foulaya and Tindo to collect adult An. gambiae s.l. Larval collections were undertaken at multiple sites in the city of Faranah 
of the assay and at 15-min intervals for up to $30 \mathrm{~min}$ (for alpha-cypermethrin, deltamethrin, permethrin, bendiocarb, and pirimiphos-methyl) or $60 \mathrm{~min}$ (for clothianidin and chlorfenapyr). Mosquitoes exposed to chlorfenapyr were held for an additional $24 \mathrm{~h}$ in paper cups, with access to $10 \%$ sugar solution. In each bioassay, a control bottle, coated with $98 \%$ ethanol, was run in parallel. Mortality was defined as the inability of a mosquito to stand or fly in a coordinated manner [11]. Synergist CDC bottle bioassays were performed using piperonyl butoxide $(\mathrm{PBO})$ to investigate the potential role of detoxifying enzyme families in resistance. Bottles were coated with $100 \mu \mathrm{g}$ of PBO and mosquitoes were exposed for $60 \mathrm{~min}$, followed by exposure to pyrethroid treated bottles. Adult mosquitoes reared from larvae were exposed for $30 \mathrm{~min}$ to permethrin and deltamethrin for comparison to wild caught adults. Multiple replicates were performed per insecticide and study village. When limited by mosquito availability, for insecticides where there was a clear lack of resistance, i.e. $100 \%$ of exposed mosquitoes dying/ becoming knocked-down very quickly into the exposure period, priority was given to testing remaining mosquitoes with doses of insecticides where initial resistance to the diagnostic dose was observed. At the end of each exposure period, separate individual surviving (resistant), knocked-down or dead (susceptible), and control mosquitoes were dipped in ethanol and then preserved in RNAlater ${ }^{\circledR}$ (Thermo Fisher Scientific, UK) at $4{ }^{\circ} \mathrm{C}$ in Faranah, for a maximum of 3 weeks, and subsequently at $-80{ }^{\circ} \mathrm{C}$ for downstream molecular analyses at the London School of Hygiene and Tropical Medicine (LSHTM).

\section{RNA extraction}

Single mosquitoes were homogenized using a Qiagen Tissue Lyser II (Qiagen, Hilden, Germany) with $3 \mathrm{~mm}$ stainless steel beads and RNA was extracted using Qiagen 96 RNeasy Kits according to the manufacturer's instructions (Qiagen, Hilden, Germany). RNA was eluted in $45 \mu \mathrm{L}$ of RNase-free water and stored at $-70{ }^{\circ} \mathrm{C}$. Specimens were selected from all three study villages, including representative susceptible and resistant individuals per insecticide per concentration. A High Capacity cDNA Reverse Transcription kit (Applied Biosystems) was used to perform reverse transcription on eluted RNA. Reactions were performed in a Bio-Rad $\mathrm{T} 100^{\mathrm{TM}}$ Thermal Cycler which cycled for $10 \mathrm{~min}$ at $25^{\circ} \mathrm{C}, 120 \mathrm{~min}$ at $37^{\circ} \mathrm{C}$, and 5 min at $85{ }^{\circ} \mathrm{C}$. The resulting cDNA was then stored at $-20{ }^{\circ} \mathrm{C}$.

\section{Identification of Anopheles gambiae species complex}

Mosquitoes were morphologically identified as Anopheles gambiae sensu lato (s.l.) in the field prior to CDC bottle bioassay testing. A sub-set of 480 samples were further identified using an end point PCR assay developed by Santolamazza et al. [12]. This assay amplifies the SINE200 insertion, a highly repetitive $\sim 200$ bp element which is widespread in the An. gambiae sensu stricto (s.s.) genome [12]. Samples were prepared with forward (5'-TCGCCTTAGACCTTGCGTTA-3') and reverse (5'-CGCTTCAAGAATTCGAGATAC-3') primers, and amplifications performed in $20 \mu \mathrm{L}$ reactions containing $2 \mu \mathrm{L}$ cDNA, $2 \mu \mathrm{L}$ of each primer $(10 \mu \mathrm{M}), 4 \mu \mathrm{L} \mathrm{H}_{2} \mathrm{O}$, and $10 \mu \mathrm{L} 2 \times$ Hot Start Taq PCR Master Mix (New England Biolabs). The cycling conditions in the Bio- $\operatorname{Rad} \mathrm{T} 100^{\mathrm{TM}}$ Thermal Cycler were: $10 \mathrm{~min}$ at $94{ }^{\circ} \mathrm{C}$; 35 cycles of $30 \mathrm{~s}$ at $94{ }^{\circ} \mathrm{C}, 30 \mathrm{~s}$ at $54{ }^{\circ} \mathrm{C}$, and $60 \mathrm{~s}$ at $72{ }^{\circ} \mathrm{C}$; then $10 \mathrm{~min}$ at $72{ }^{\circ} \mathrm{C}$. Products were run on $2 \%$ agarose gels in an Invitrogen E-gel iBase ${ }^{\mathrm{TM}}$ Real-Time Transilluminator. Amplification products of $479 \mathrm{bp}$ or $249 \mathrm{bp}$ were considered indicative of Anopheles coluzzii or An. gambiae s.s., respectively; both bands indicate a hybrid individual. The An. gambiae s.s. form has an identical banding pattern to that of Anopheles melas and Anopheles quadriannulatus (249 bp), however, due to the geographical location of sampling, it is highly unlikely that these species were present.

\section{Plasmodium falciparum detection}

A total of 508 whole body mosquito samples (collected in HLCs) were tested for the presence of $P$. falciparum using a real-time assay targeting the cytochrome $\mathrm{c}$ oxidase subunit 1 ( $\operatorname{cox} 1)$ mitochondrial gene of $P$. falciparum according to Boissière et al. [13]. This sample includes all specimens which underwent PCR for species identification and were subsequently processed for metabolic gene expression (see below). This assay is highly sensitive and specific, capable of detecting the target gene at all stages of the $P$. falciparum life cycle [13]. Samples were prepared with forward (5'-TTACATCAGGAATGTTATTGC-3') and reverse $\left(5^{\prime}\right.$-ATATTGGATCTCCTGCAAAT- $\left.3^{\prime}\right)$ primers, and amplifications performed in $10 \mu \mathrm{L}$ reactions containing $2 \mu \mathrm{L}$ cDNA, $1 \mu \mathrm{L}$ of each primer $(10 \mu \mathrm{M}), 1 \mu \mathrm{L}$ $\mathrm{H}_{2} \mathrm{O}$, and $5 \mu \mathrm{L} 2 \times$ Roche FastStart Essential DNA green master mix containing SYBR Green. Samples were run on a Roche Lightcycler ${ }^{\circledR} 96$ Real-Time PCR system for $15 \mathrm{~min}$ at $95^{\circ} \mathrm{C}$, followed by 35 cycles of $15 \mathrm{~s}$ at $95^{\circ} \mathrm{C}$ and $30 \mathrm{~s}$ at $58{ }^{\circ} \mathrm{C}$. Fluorescence results were analysed using Roche Lightcycler ${ }^{\circledR} 96$ software. Positive controls were used from gDNA extracted from a cultured $P$. falciparuminfected blood sample (parasitaemia of $\sim 10 \%$ ) in addition to the inclusion of no template controls (NTCs).

\section{Characterization of resistance mutations: target site mutations}

A sub-sample of 60 mosquitoes was selected to be tested for the West African L1014F $k d r$ mutation, given the high 
frequency of this allele and its fixation in many parts of Guinea and West Africa [10, 14]. The PCR master mix was prepared according to MR4 guidelines [15]. Primers IPCF (5'-GATAATGTGGATAGATTCCCCGAC CATG-3'), AltRev (5'-TGCCGTTGGTGCAGACAA GGATG-3'), WEST WT (5'-GGTCCATGTTAATTT GCATTACTTACGAATA-3'), and West:West (5'-CTT GGCCACTGTAGTGATAGGAAATGTT-3') were used to detect the L1014F allele. Amplifications were performed in $25 \mu \mathrm{L}$ reactions containing $2 \mu \mathrm{L}$ cDNA, $1 \mu \mathrm{L}$ IPCF $(2.5 \mathrm{pmol} / \mu \mathrm{L}), 1 \mu \mathrm{L}$ AltRev $(2.5 \mathrm{pmol} / \mu \mathrm{L}), 1 \mu \mathrm{L}$ West WT $(25.0 \mathrm{pmol} / \mu \mathrm{L}), 3 \mu \mathrm{L}$ West:West $(8.0 \mathrm{pmol} / \mu \mathrm{L})$, $4.5 \mu \mathrm{L} \mathrm{H}_{2} \mathrm{O}$, and $12.5 \mu \mathrm{L} 2 \times$ Hot Start Taq PCR Master Mix (New England Biolabs). Samples were run on a Bio$\operatorname{Rad} \mathrm{T} 100^{\mathrm{TM}}$ Thermal Cycler and cycled for $5 \mathrm{~min}$ at $95^{\circ} \mathrm{C}$, followed by 35 cycles of $30 \mathrm{~s}$ at $95{ }^{\circ} \mathrm{C}, 30 \mathrm{~s}$ at $59{ }^{\circ} \mathrm{C}$, and $30 \mathrm{~s}$ at $72{ }^{\circ} \mathrm{C}$, and a final extension step of $5 \mathrm{~min}$ at $72{ }^{\circ} \mathrm{C}$. PCR products were separated on $2 \%$ agarose gels in an Invitrogen E-gel iBase ${ }^{\mathrm{TM}}$ Real-Time Transilluminator. A control band at $314 \mathrm{bp}$ indicated a successful reaction, a band at $214 \mathrm{bp}$ indicated the susceptible wild type, and a band at $156 \mathrm{bp}$ indicated the resistance mutation.

Detection of the N1575Y mutation was carried out with 570 samples (including the 60 individuals who tested positive for L1014F $k d r$ ), using a TaqMan PCR assay developed by Jones et al. [16]. Forward primer ( $5^{\prime}$-TGG ATCGCTAGAAATGTTCATGACA-3'), reverse primer (5'-CGAGGAATTGCCTTTAGAGGTTTCT-3'), and two probes: Yprobe $\left(5^{\prime}\right.$ - TTTTTCATTGCATAATAG TAC-3') and Nprobe (5'-ATTTTTTTCATTGCATTA TAGTAC- $3^{\prime}$ ) were used to detect the presence of the wild type and the mutation allele. HEX and FAM fluorophores were used due to their different excitation wavelengths, ensuring no interference: excitation of HEX showed no mutation, while excitation of HEX and FAM at similar $\mathrm{Ct}$ values indicated the $\mathrm{N} 1575 \mathrm{Y}$ mutation. $20 \mu \mathrm{L}$ reactions containing $2 \mu \mathrm{L}$ cDNA, $1 \mu \mathrm{L}$ each primer $(10 \mu \mathrm{M}), 0.5 \mu \mathrm{L}$ each probe, $5 \mu \mathrm{L} \mathrm{H}_{2} \mathrm{O}$, and $10 \mu \mathrm{L}$ QuantiTect Probe Master Mix were prepared in plates and run on an Agilent Technologies Stratagene Mx3005P qPCR system and cycled according to the Quantitect ${ }^{\mathrm{TM}}$ Probe PCR Handbook guidelines $\left(15 \mathrm{~min}\right.$ at $95^{\circ} \mathrm{C} ; 35$ cycles of $15 \mathrm{~s}$ at $95^{\circ} \mathrm{C}$ and $60 \mathrm{~s}$ at $60^{\circ} \mathrm{C}$ ). Positive controls from gDNA extracted from known An. gambiae s.s. with the N1575Y mutation and without the mutation were included on each run in addition to no template controls (NTCs).

A subsample of 30 mosquitoes which were resistant or susceptible to bendiocarb were tested for the presence of the G119S Ace-1 mutation using a TaqMan PCR assay, according to Weill et al. [17]. Samples were prepared with degenerate primers Moustdir1 (5'-CCGGGNGCSACY ATGTGGAA- $3^{\prime}$ ) and Moustrev1 (5'-ACGATMACG TTCTCYTCCGA-3'), and amplifications performed in $20 \mu \mathrm{L}$ reactions containing $2 \mu \mathrm{L}$ cDNA, $2 \mu \mathrm{L}$ each primer $(10 \mu \mathrm{M}), 4 \mu \mathrm{L} \mathrm{H}_{2} \mathrm{O}$, and $10 \mu \mathrm{L} 2 \times$ Hot Start Taq PCR Master Mix (New England Biolabs). Samples were loaded into a Biorad $\mathrm{T} 100^{\mathrm{TM}}$ Thermal Cycler for $3 \mathrm{~min}$ at $95^{\circ} \mathrm{C}$, followed by 30 cycles of $30 \mathrm{~s}$ at $95^{\circ} \mathrm{C}, 30 \mathrm{~s}$ at $52^{\circ} \mathrm{C}$, and $1 \mathrm{~min}$ at $72{ }^{\circ} \mathrm{C}$, and a final step of $10 \mathrm{~min}$ at $72{ }^{\circ} \mathrm{C}$. The resulting PCR fragments were then digested with AluI restriction enzyme (Thermo Scientific) for $16 \mathrm{~h}$, according to the manufacturer's instructions, and run on $2 \%$ agarose gels in an Invitrogen E-gel iBase ${ }^{\mathrm{TM}}$ RealTime Transilluminator. $194 \mathrm{bp}$ undigested PCR products indicated the susceptible allele and $74 \mathrm{bp}$ and $120 \mathrm{bp}$ digested fragments indicated the presence of the resistant allele. Presence of all three product sizes indicated the sample was heterozygous. Positive controls from gDNA extracted from known An. gambiae s.s. that were homozygous susceptible (SS), homozygous resistant (RR) and heterozygous individuals (RS) for G119S Ace-1 were included in addition to no template controls (NTCs).

\section{Characterization of resistance mechanisms: metabolic gene expression}

The relative gene expression of two cytochromedependent monooxygenases: CYP6P3, CYP6M2, and glutathione-s-transferase, GSTD3, was analysed in 461 individuals from Guinea and 41 susceptible G3 individuals from a colony at LSHTM, using quantitative reverse transcriptase PCR (qRT-PCR) relative to the housekeeping gene ribosomal protein S7 (RPS7), according to Yahouédo et al. [18]. RPS7 was selected as an endogenous reference gene, commonly used to normalize RNA expression levels, between Anopheles populations. These genes were targeted based upon their significant overexpression in other neighbouring West African vector populations $[18,19]$. Each gene used the following primers: RPS7 forward (5'-ATTGCCGAGCGCCGCATTCT-3') and reverse (5'-GACGCGGATACGCTTGCCGA-3') primers, CYP6M2 forward (5'-TCGGGATGTGTGCGT TCGGC- $3^{\prime}$ ) and reverse (5'-TCGTGTCTCGCACCG CGTTC- $3^{\prime}$ ) primers, CYP6P3 forward (5'-TGTGATTGA CGAAACCCTTCGGAAG- $3^{\prime}$ ) and reverse (5'-ATAGTC CACAGACGGTACGCGGG-3') primers, and GSTD3 forward (5'-CTAAGCTTAATCCGCAACATACCA-3') and reverse (5'-GTGTCATCCTTGCCGTACAC-3') primers. For each gene, $10 \mu \mathrm{L}$ reactions were prepared containing $2 \mu \mathrm{L}$ cDNA, $1 \mu \mathrm{L}$ each primer $(10 \mu \mathrm{M}), 1 \mu \mathrm{L}$ $\mathrm{H}_{2} \mathrm{O}$, and $5 \mu \mathrm{L} 2 \times$ Roche FastStart Essential DNA green master mix containing SYBR Green. Prepared reactions were loaded into the Agilent Technologies Stratagene Mx3005P qPCR system which cycled for $10 \mathrm{~min}$ at $95{ }^{\circ} \mathrm{C}$; 35 cycles of $10 \mathrm{~s}$ at $95{ }^{\circ} \mathrm{C}, 22 \mathrm{~s}$ at $60^{\circ} \mathrm{C}$, and $10 \mathrm{~s}$ at $72{ }^{\circ} \mathrm{C}$; followed by a melt curve. Serial dilutions were performed on selected samples for each of the four genes 
and relative standard curves produced using the Stratagene MxPro qPCR software (Agilent Technologies). Using the same software, sample Ct values could then be used to generate relative quantities, accounting for each assays' efficiency, and the expression level of each metabolic gene tested could be normalized to the housekeeping gene RPS7.

\section{Data analysis}

Data were recorded on pre-prepared data sheets and entered into an Excel spreadsheet. Control mortality in bioassays never exceeded 5\%, thus correction using Abbott's formula was not necessary. Mosquito mortality was analysed according to WHO criteria: $98-100 \%$ mortality at $30 \mathrm{~min}$ of exposure indicates 'susceptibility', 90-97\% mortality suggests 'possible resistance' and $<90 \%$ indicates the presence of 'resistance' [4]. GraphPad Prism 7 (GraphPad Software) was used for statistical analysis (t-tests, Fisher's exact tests and Chi-squared tests). Microsoft Excel was used to calculate proportions and construct resistance graphs. Stratagene MxPro qPCR software (Agilent Technologies) was used to produce relative standard curves for genotypic analysis.

\section{Results}

\section{Mosquito collections and species identification}

A total of 2597 female An. gambiae s.l. mosquitoes were either wild-caught using HLCs from three villages in Faranah Prefecture (Balayani $=956$, Foulaya $=914$, and Tindo $=589$ ) or raised from larvae collected in Faranah $(\mathrm{n}=138)$. Of those, 480 were selected for molecular species identification, with 466 (97.1\%) determined to be An. gambiae s.s., 6 (1.3\%) identified as An. coluzzii, and 6 (1.3\%) identified as hybrids; results were inconclusive for $2(0.4 \%)$ individuals.

\section{Insecticide resistance intensity}

Levels of susceptibility to seven insecticides (permethrin, deltamethrin, alpha-cypermethrin, bendiocarb, pirimiphos-methyl, clothianidin and chlorfenapyr) were assessed across three villages in Faranah (Balayani, Foulaya, and Tindo). Overall, each study site displayed comparable resistance profiles for deltamethrin (pyrethroid) and bendiocarb (carbamate); no significant association between mosquito mortality and sample site was observed $\left(x^{2}=6.495, p=0.0899\right.$ for deltamethrin $1 \times$; $\chi^{2}=1.338, p=0.5122, \chi^{2}=2.38, p=0.304$ and $x^{2}=0.903$, $p=0.637$ for bendiocarb at $1 \times, 2 \times$ and $5 \times$, respectively). However, mosquito mortality following permethrin (pyrethroid) exposure varied among villages in Faranah $\left(X^{2}=8.573, p=0.035\right.$ and $x^{2}=29.58, p<0.0001$, for $1 \times$ and $2 \times$, respectively).
Considering HLC-collected adult mosquitoes from Faranah Prefecture as a whole, resistance was consistently observed to permethrin and deltamethrin. Permethrin gave the lowest mortality of all insecticides tested with $4 \%$ [95\% CI 1\%, 11\%] and 15\% [95\% CI 9\%, 24\%] mosquito mortality at $1 \times$ and $2 \times$ the diagnostic doses, respectively (Fig. 2 and Table 1). Resistance to deltamethrin was also evident, but to a lesser degree; average mosquito mortality to the diagnostic dose was $86 \%$ [95\% CI 77\%, 91\%] (Fig. 2). Possible resistance was observed to bendiocarb, with mosquito mortality ranging between 94 and $97 \%$ at $1 \times, 2 \times$, and $5 \times$ concentrations. Mosquitoes were found to be susceptible to the diagnostic doses of all other insecticides with mortalities $>98 \%$ for alpha-cypermethrin, chlorfenapyr, clothianidin, and pirimiphosmethyl (Fig. 2 and Table 1).

Minor variations in levels of resistance were apparent between study villages. The most intense permethrin resistance was measured in Foulaya, with average mosquito mortality of $0 \%$ [ $95 \% \mathrm{CI} 0 \%, 13 \%$ ] following exposure to either $1 \times$ or $2 \times$ the diagnostic dose, relative to $6 \%$ [95\% CI 2\%, 19\%] and 10\% [95\% CI 4\%, 24\%] in Balayani and $7 \%$ [95\% CI 1\%, 30\%] and 43\% [95\% CI 24\%, 63\%] in Tindo, respectively (Table 1). Possible resistance to permethrin $5 \times$ was identified in Foulaya and Balayani (average mosquito mortality of $96 \%$ [95\% CI 81\%, 99\%] and $97 \%$ [95\% CI 87\%, 100\%], respectively). By comparison, the lowest levels of resistance to the diagnostic dose of deltamethrin were observed in Foulaya, with average mosquito mortality of $95 \%$ [ $95 \%$ CI $84 \%, 99 \%$ ], compared to $79 \%$ [95\% CI 62\%, 89\%] and 75\% [95\% CI 51\%, 90\%] in Balayani and Tindo, respectively.

Two to five-day old mosquitoes raised in the insectary from larvae demonstrated moderately similar resistance profiles, when compared to locally-collected adult populations of varying physiological age (Table 1). Both permethrin and deltamethrin resistance was present, with average mosquito mortality of $21 \%$ [ $95 \%$ CI 10\%, 40\%] and $60 \%$ [95\% CI 36\%, 80\%] for permethrin $1 \times$ and $2 \times$ doses, respectively, and 73\% [95\% CI 43\%, 90\%] mortality for deltamethrin $1 \times$. Comparing resistance profiles in larvae to that observed in each village, a statistical difference was observed for permethrin $1 \times$ in Foulaya $\left(\chi^{2}=6.014, p=0.0142\right)$ and in all villages combined at $1 \times\left(x^{2}=7.407, p=0.0065\right)$; permethrin $2 \times$ in Balayani $\left(\chi^{2}=14.62, p=0.0001\right)$ and Foulaya $\left(\chi^{2}=20.753\right.$, $p<0.0001)$, and all villages combined at $2 \times\left(x^{2}=15.2\right.$, $p=0.0001)$; and deltamethrin $1 \times$ in Foulaya $\left(\chi^{2}=4.72\right.$, $p=0.0298$ ). Reared mosquitoes were found to be susceptible to all other concentrations of permethrin and deltamethrin with mortalities of $100 \%$.

Synergist bioassays were performed on a sub-sample of mosquitoes from Balayani. Pre-exposure to $\mathrm{PBO}$ 


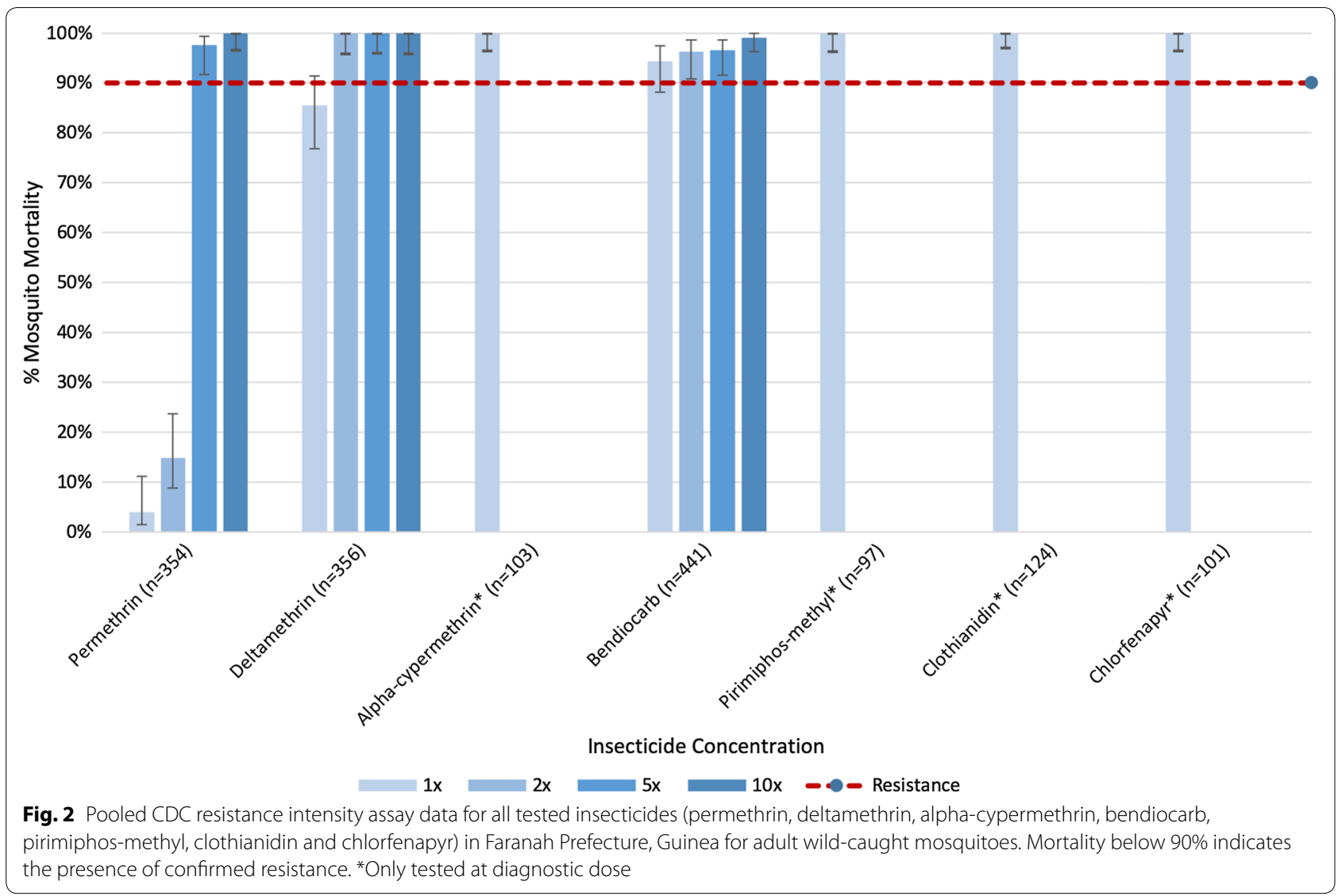

and subsequent permethrin or deltamethrin treatment resulted in partial or complete abolishment of resistance. Mortality to permethrin increased from 6 to $87 \%$ at $1 \times$, and from 10 to $100 \%$ at $2 \times$; mortality following deltamethrin exposure increased from 79 to $100 \%$ at $1 \times$.

\section{Plasmodium falciparum detection}

Of the 508 mosquitoes tested for the presence of $P$. falciparum, 37 individuals were positive (indicating the presence of any parasite lifecycle stage), giving an infection rate of 7.3\%. For PCR-confirmed An. gambiae s.s., P. falciparum infection prevalence was $6.1 \%(26 / 423)$. There was no significant difference in $P$. falciparum infection among study villages $\left(x^{2}=1.358, p=0.507\right)$. Considering pooled insecticide results (permethrin, deltamethrin, and bendiocarb), susceptible mosquitoes were more likely to be infected with $P$. falciparum $(7.6 \% ; 33 / 432)$ than resistant mosquitoes $(2.8 \% ; 4 / 144)\left(\chi^{2}=4.236, p=0.039\right)$. However, no statistical association between survival to insecticide exposure and P. falciparum infection was observed per individual chemical (Fisher's exact: permethrin $2 \times p=0.37,5 \times p=0.54$; deltamethrin $1 \times p=0.43$; bendiocarb $1 \times p=0.58,2 \times p=0.73,5 \times p=0.6$ and $10 \times$ $p=0.54)$.

\section{Characterization of resistance mechanisms: target site mutations}

Of the sub-sample of $60 A n$. gambiae s.s. which were tested for the L1014F $k d r$ allele, this mutation was identified in all An. gambiae s.s. samples (100\%). Of the 570 individuals which were assayed for the presence of N1575Y, this mutation was detected in $20 \%$ (113/561; 9 specimens failed to amplify) (Table 2). For PCR-confirmed An. gambiae s.s., N1575Y was observed in $19 \%(91 / 473)$ of specimens. Four $(0.7 \%)$ individuals were heterozygous for this mutation, while the remainder were homozygous. Across Faranah, the frequency of $\mathrm{N} 1575 \mathrm{Y}$ did not vary significantly $\left(\chi^{2}=4.4819\right.$, $p=0.214$ for comparisons between Balayani, Foulaya, Tindo, and larvae from Faranah). In addition, no significant association was observed between the presence of the N1575Y mutation and the ability to survive exposure to pyrethroid insecticides (permethrin $1 \times \chi^{2}=0.015, p=0.902 ; 2 \times \chi^{2}=0.189, p=0.664$; $5 \times \chi^{2}=0.814, p=0.359$; deltamethrin $1 \times \chi^{2}=0.934$, $p=0.334)$. Significant deviations from Hardy-Weinberg equilibrium were observed in almost all phenotyped specimens, indicative of ongoing selection (Table 2). 
Table 1 Percentage mortality (and numbers tested) of Anopheles gambiae s.I. in CDC resistance intensity assays conducted at four sites in Faranah Prefecture, Guinea

\begin{tabular}{|c|c|c|c|c|c|}
\hline \multirow[t]{2}{*}{ Study site } & \multirow[t]{2}{*}{ Insecticide } & \multicolumn{4}{|c|}{$\%$ Mortality (numbers tested) after diagnostic time } \\
\hline & & $1 x$ & $2 x$ & $5 x$ & $10 x$ \\
\hline \multirow[t]{9}{*}{ Balayani } & Permethrin & $6 \%(34)$ & $10 \%(39)$ & $97 \%(38)$ & $100 \%(55)$ \\
\hline & Permethrin + PBO & $87 \%(15)$ & $100 \%(18)$ & $100 \%(22)$ & $100 \%(28)$ \\
\hline & Deltamethrin & $79 \%(33)$ & $100 \%(35)$ & $100 \%(32)$ & $100 \%(46)$ \\
\hline & Deltamethrin + PBO & $100 \%(26)$ & - & - & - \\
\hline & Alpha-cypermethrin & $100 \%(20)$ & - & - & - \\
\hline & Bendiocarb & $97 \%(38)$ & $98 \%(42)$ & $96 \%(46)$ & $100 \%(43)$ \\
\hline & Pirimiphos-methyl & $100 \%(40)$ & - & - & - \\
\hline & Clothianidin & $100 \%(38)$ & - & - & - \\
\hline & Chlorfenapyr & $100 \%(21)$ & - & - & - \\
\hline \multirow[t]{7}{*}{ Foulaya } & Permethrin & $0 \%(26)$ & $0 \%(28)$ & $96 \%(25)$ & $100 \%(24)$ \\
\hline & Deltamethrin & $95 \%(41)$ & $100 \%(39)$ & $100 \%(41)$ & $100 \%(24)$ \\
\hline & Alpha-cypermethrin & $100 \%(42)$ & - & - & - \\
\hline & Bendiocarb & $92 \%(48)$ & $93 \%(43)$ & $96 \%(53)$ & $100 \%(47)$ \\
\hline & Pirimiphos-methyl & $100 \%(19)$ & - & - & - \\
\hline & Clothianidin & $100 \%(33)$ & - & - & - \\
\hline & Chlorfenapyr & $100 \%(40)$ & - & - & - \\
\hline \multirow[t]{7}{*}{ Tindo } & Permethrin & $7 \%(15)$ & $43 \%(21)$ & $100 \%(20)$ & $100 \%(29)$ \\
\hline & Deltamethrin & $75 \%(16)$ & $100 \%(15)$ & $100 \%(17)$ & $100 \%(17)$ \\
\hline & Alpha-cypermethrin & $100 \%(41)$ & - & - & - \\
\hline & Bendiocarb & $95 \%(21)$ & $100 \%(23)$ & $100 \%(21)$ & $95 \%(21)$ \\
\hline & Pirimiphos-methyl & $100 \%(38)$ & - & - & - \\
\hline & Clothianidin & $100 \%(53)$ & - & - & - \\
\hline & Chlorfenapyr & $100 \%(40)$ & - & - & - \\
\hline Faranah & Permethrin & $21 \%(28)$ & $60 \%(15)$ & $100 \%(12)$ & $100 \%(17)$ \\
\hline Larvae & Deltamethrin & $73 \%(11)$ & $100 \%(11)$ & $100 \%(13)$ & $100 \%(14)$ \\
\hline
\end{tabular}

Of the subsample of 30 An. gambiae s.s. which survived or died following bendiocarb exposure, the G119S Ace-1 mutation was present in $62 \%$ (18/29 individuals; 1 specimen failed to amplify) (Table 3), with allele frequencies ranging from 0.25 to 1.0 . Seventeen specimens were homozygous, the remaining individual was heterozygous. There was a statistically significant association between the presence of the G119S Ace-1 mutation and mosquito survival after bendiocarb exposure at $1 \times$ and $2 \times$ (Fisher's exact: $p=0.00108$ and $p=0.0238$ respectively). Significant deviations from Hardy-Weinberg equilibrium for G119S Ace-1, were limited to mosquitoes which died following exposure to bendiocarb $2 \times$ and $5 \times$ (Table 3 ).

\section{Characterization of resistance mechanisms: metabolic gene expression}

461 samples identified as An. gambiae s.s. were tested for the expression of CYP6M2, CYP6P3, and GSTD3 genes relative to the housekeeping gene RPS7 and compared to 41 An. gambiae s.s. samples from a susceptible
G3 colony. These three genes were significantly overexpressed in the majority of wild-caught An. gambiae s.s. when compared to the susceptible G3 laboratory strain (Table 4 and Fig. 3).

The greatest changes in gene expression were observed for GSTD3, with an average mean fold change of 1.19 among wild An. gambiae s.s. compared to 0.44 in G3 colony individuals; average levels of $C Y P 6 M 2$ and $C Y P 6 P 3$ were 0.84 and 0.79 compared to 0.09 and 0.12 between field and colony mosquitoes, respectively. Among Guinean vectors, a significantly higher expression of CYP6P3 was observed between individuals which survived bendiocarb exposure at $1 \times$ and $2 \times$, compared to those that died (1.44 vs. $0.62 ; p=0.0524$ and 1.68 vs. $0.55 ; p=0.0366$, respectively) (Table 4 ). However, no significant changes in gene expression of CYP6M2 and GSTD3 were apparent between wild $A n$. gambiae s.s. which survived or died after insecticide exposure at any dose. 
Table 2 N1575Y allele frequencies and $p$ values for Chi-square tests for deviations from Hardy-Weinberg equilibrium in An. gambiae s.s. from four sites in Faranah Prefecture, Guinea

Study village/sampling site

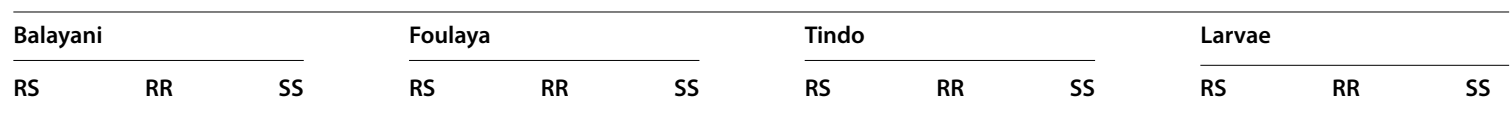

Permethrin $1 x$

Alive

Dead

Permethrin $2 x$

Alive

Dead

Permethrin $5 x$

Alive

Dead

Permethrin $10 x$

Alive

Dead

Deltamethrin $1 \times$

Alive

Dead

Deltamethrin $2 x$

Alive

Dead

Deltamethrin $5 x$

Alive

Dead

Deltamethrin $10 x$

Alive

Dead

Alpha-cypermethrin $1 \times$

Alive

Dead

Alpha-cypermethrin $2 x$

Alive

Dead

Alpha-cypermethrin $5 \times$

Alive

Dead

Alpha-cypermethrin $10 x$

Alive

Dead

Bendiocarb $1 \times$

Alive

Dead

Bendiocarb $2 x$

Alive

Dead

Bendiocarb 5x

Alive

Dead

Bendiocarb 10x

$\begin{array}{ll}\text { Alive } & 0 \\ \text { Dead } & 0\end{array}$


Table 2 (continued)

\begin{tabular}{|c|c|c|c|c|c|c|c|}
\hline & \multicolumn{3}{|c|}{$\begin{array}{l}\text { Study village/sampling site } \\
\text { Total }\end{array}$} & \multicolumn{2}{|c|}{ N1575Y allele frequency } & \multirow[t]{2}{*}{$x^{2}$ test } & \multirow[t]{2}{*}{$p$ value } \\
\hline & $\mathrm{RS}$ & RR & $\overline{\text { SS }}$ & $\mathrm{R}$ & $\mathrm{s}$ & & \\
\hline \multicolumn{8}{|c|}{ Permethrin $1 x$} \\
\hline Alive & 0 & 10 & 39 & 0.2 & 0.8 & 49 & $<0.00001$ \\
\hline Dead & 0 & 2 & 7 & 0.22 & 0.78 & 9 & 0.0027 \\
\hline \multicolumn{8}{|c|}{ Permethrin $2 x$} \\
\hline Alive & 0 & 6 & 50 & 0.11 & 0.89 & 56 & $<0.00001$ \\
\hline Dead & 0 & 3 & 18 & 0.14 & 0.86 & 21 & $<0.00001$ \\
\hline \multicolumn{8}{|c|}{ Permethrin $5 x$} \\
\hline Alive & 0 & 1 & 1 & 0.5 & 0.5 & 2 & 0.157299 \\
\hline Dead & 0 & 9 & 32 & 0.22 & 0.78 & 41 & $<0.00001$ \\
\hline \multicolumn{8}{|c|}{ Permethrin $10 x$} \\
\hline Alive & 0 & 0 & 0 & - & - & - & - \\
\hline Dead & 0 & 6 & 16 & 0.27 & 0.73 & 22 & $<0.00001$ \\
\hline \multicolumn{8}{|c|}{ Deltamethrin $1 \times$} \\
\hline Alive & 0 & 5 & 10 & 0.33 & 0.67 & 15 & 0.00108 \\
\hline Dead & 0 & 9 & 34 & 0.21 & 0.79 & 43 & $<0.00001$ \\
\hline \multicolumn{8}{|c|}{ Deltamethrin $2 x$} \\
\hline Alive & 0 & 0 & 0 & - & - & - & - \\
\hline Dead & 0 & 5 & 19 & 0.21 & 0.79 & 24 & $<0.00001$ \\
\hline \multicolumn{8}{|c|}{ Deltamethrin $5 x$} \\
\hline Alive & 0 & 0 & 0 & - & - & - & - \\
\hline Dead & 0 & 5 & 19 & 0.21 & 0.79 & 24 & $<0.00001$ \\
\hline \multicolumn{8}{|c|}{ Deltamethrin $10 x$} \\
\hline Alive & 0 & 0 & 0 & - & - & - & - \\
\hline Dead & 0 & 6 & 18 & 0.25 & 0.75 & 23 & $<0.00001$ \\
\hline \multicolumn{8}{|c|}{ Alpha-cypermethrin $1 \times$} \\
\hline Alive & 0 & 0 & 0 & - & - & - & - \\
\hline Dead & 0 & 6 & 18 & 0.25 & 0.75 & 23 & $<0.00001$ \\
\hline \multicolumn{8}{|c|}{ Alpha-cypermethrin $2 x$} \\
\hline Alive & 0 & 0 & 0 & - & - & - & - \\
\hline Dead & 1 & 5 & 18 & 0.23 & 0.77 & 18.6729 & 0.000016 \\
\hline \multicolumn{8}{|c|}{ Alpha-cypermethrin $5 x$} \\
\hline Alive & 0 & 0 & 0 & - & - & - & - \\
\hline Dead & 0 & 4 & 19 & 0.17 & 0.83 & 23 & $<0.00001$ \\
\hline \multicolumn{8}{|c|}{ Alpha-cypermethrin 10x } \\
\hline Alive & 0 & 0 & 0 & - & - & - & - \\
\hline Dead & 1 & 3 & 20 & 0.15 & 0.85 & 16.6434 & 0.000045 \\
\hline \multicolumn{8}{|c|}{ Bendiocarb $1 \times$} \\
\hline Alive & 0 & 4 & 2 & 0.67 & 0.33 & 6 & \\
\hline Dead & 0 & 6 & 27 & 0.18 & 0.82 & 33 & \\
\hline \multicolumn{8}{|c|}{ Bendiocarb $2 x$} \\
\hline Alive & 0 & 1 & 3 & 0.25 & 0.75 & 4 & \\
\hline Dead & 1 & 6 & 26 & 0.2 & 0.8 & 29.9806 & $<0.00001$ \\
\hline \multicolumn{8}{|c|}{ Bendiocarb $5 x$} \\
\hline Alive & 0 & 0 & 4 & 0 & 1 & - & - \\
\hline Dead & 1 & 4 & 27 & 0.14 & 0.86 & 24.2602 & $<0.00001$ \\
\hline \multicolumn{8}{|c|}{ Bendiocarb 10x } \\
\hline Alive & 0 & 1 & 0 & 1 & 0 & - & - \\
\hline Dead & 0 & 0 & 23 & 0 & 1 & - & - \\
\hline
\end{tabular}

Italic values indicate significance of $p$ values $(p<0.05)$ 
Table 3 G119S Ace-1 allele frequencies and $p$ values for Chi-square tests for deviations from Hardy-Weinberg equilibrium in An. gambiae s.s. from four sites in Faranah Prefecture, Guinea

\begin{tabular}{|c|c|c|c|c|c|c|c|c|c|c|c|c|c|c|c|c|}
\hline & \multicolumn{12}{|c|}{ Study village/sampling site } & \multirow{2}{*}{\multicolumn{2}{|c|}{$\begin{array}{l}\text { G119S Ace-1 } \\
\text { allele frequency }\end{array}$}} & \multirow[t]{3}{*}{$x^{2}$ test } & \multirow[t]{3}{*}{$p$-value } \\
\hline & \multicolumn{3}{|c|}{ Balayani } & \multicolumn{3}{|c|}{ Foulaya } & \multicolumn{3}{|c|}{ Tindo } & \multicolumn{3}{|c|}{ Larvae } & & & & \\
\hline & RS & RR & SS & RS & RR & SS & RS & RR & SS & RS & RR & SS & $\mathbf{R}$ & $S$ & & \\
\hline \multicolumn{17}{|c|}{ Bendiocarb $1 \times$} \\
\hline Alive & 0 & 1 & 0 & 0 & 4 & 0 & 0 & 1 & 0 & 0 & 6 & 0 & 1 & 0 & - & - \\
\hline Dead & 0 & 0 & 5 & 0 & 0 & 0 & 0 & 0 & 0 & 0 & 0 & 5 & 0 & 1 & - & - \\
\hline \multicolumn{17}{|c|}{ Bendiocarb $2 x$} \\
\hline Alive & 0 & 1 & 0 & 0 & 4 & 0 & 0 & 0 & 0 & 0 & 5 & 0 & 1 & 0 & - & - \\
\hline Dead & 0 & 1 & 1 & 0 & 0 & 1 & 0 & 0 & 1 & 0 & 1 & 3 & 0.25 & 0.75 & 4 & 0.0455 \\
\hline \multicolumn{17}{|c|}{ Bendiocarb $5 \times$} \\
\hline Alive & 0 & 2 & 0 & 1 & 0 & 0 & 0 & 0 & 0 & 1 & 2 & 0 & 0.83 & 0.17 & 0.12 & 0.729034 \\
\hline Dead & 0 & 2 & 2 & 0 & 0 & 0 & 0 & 0 & 0 & 0 & 2 & 2 & 0.5 & 0.5 & 4 & 0.0455 \\
\hline \multicolumn{17}{|c|}{ Bendiocarb $10 x$} \\
\hline Alive & 0 & 0 & 0 & 0 & 0 & 0 & 0 & 0 & 0 & 0 & 0 & 0 & - & - & - & - \\
\hline Dead & 0 & 0 & 0 & 0 & 0 & 1 & 0 & 1 & 0 & 0 & 1 & 1 & 0.5 & 0.5 & 2 & 0.157299 \\
\hline
\end{tabular}

Italic values indicate significance of $p$ values $(p<0.05)$

\section{Discussion}

The susceptibility of An. gambiae s.l. populations from Faranah, Guinea to seven public health insecticides were assessed and underlying resistance mechanisms characterized. Intense resistance to permethrin and deltamethrin was apparent, with survivors at $5 \times$ and $2 \times$ the diagnostic doses, respectively; minor heterogeneity in mosquito mortality was also evident across this restricted geographic area. By comparison, no evidence of alpha-cypermethrin resistance was observed in Faranah, with $100 \%$ mosquito mortality following exposure. Increased tolerance to particular pyrethroids in this region is not unexpected, given LLINs are the sole insecticide-based malaria control strategy implemented in Guinea. Deltamethrin LLINs were distributed nationwide in 2013 (Netprotect $^{\circledR}$ ) and 2016 $\left(\right.$ PermaNet $^{\circledR} 2.0$ and Yorkool $^{\circledR}$ ) by the National Malaria Control Programme (NMCP) [10], thus a resulting increase in deltamethrin resistance would be anticipated. However, the higher levels of permethrin resistance demonstrated in this study could be the result of control efforts prior to 2013 or concurrent use of this insecticide (and/or others capable of facilitating cross-resistance) in agriculture activities. Alternatively, L1014F $k d r$, which our study indicated was fixed in Faranah in 2018, as well as in other parts of Guinea [10, 20], has been reported to contribute more to resistance to type I (permethrin) vs type II (alpha-cypermethrin and deltamethrin) pyrethroids [21].

In Faranah, susceptibility to all other classes of insecticides under evaluation was confirmed, excluding the carbamate, bendiocarb, which showed the development of possible resistance with mortality ranging between 94 and $97 \%$ in the region. This emerging resistance may also be attributable to carbamate use in the agricultural setting [10], as has been documented previously in other parts of Guinea [20]. The organophosphate, pirimiphosmethyl, achieved complete mosquito mortality in this study. Currently, large-scale government-funded, widespread IRS activities are not underway in Guinea. However, knowledge of susceptibility in relation to current LLIN use will help to guide potential IRS implementation in the future [9]. Local mosquito populations were also susceptible to two new insecticides under consideration for public health use, clothianidin (neonicotinoid) and chlorfenapyr (pyrrole), strengthening the evidence that net impregnations and IRS formulations with these insecticides may be successful in future vector control efforts. Likewise, absence of alpha-cypermethrin resistance supports the deployment of Interceptor $\mathrm{G} 2{ }^{\circledR}$ LLINs (containing a combination of alpha-cypermethrin and chlorfenapyr) in prospective LLIN distributions.

Regarding underlying resistance mechanisms, decreased susceptibility to pyrethroids in Faranah was mediated both by target site mutations and overexpression of metabolic enzymes. The L1014F $k d r$ mutation was detected in all tested samples, which is consistent with high frequencies of this mutation observed throughout the country $[10,20]$. This study did not screen for the East African L1014S $k d r$ mutation, which is known to have variable frequencies in West Africa and may warrant surveillance in Guinea in the future [22-24]. A 

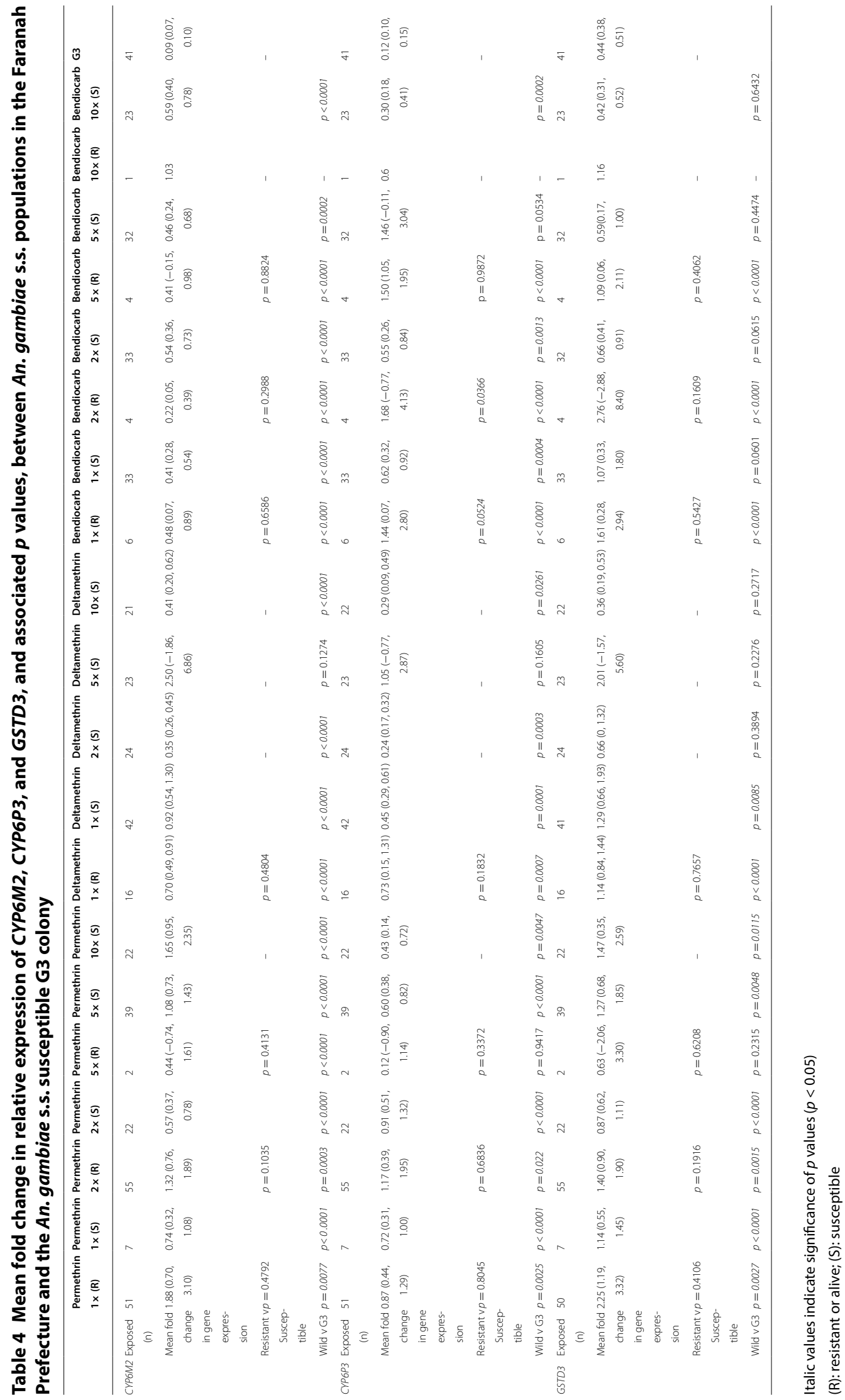
second mutation in the voltage-gated sodium channel, $\mathrm{N} 1575$ Y, was confirmed in $20 \%$ of vectors, with strong evidence for ongoing selection, as demonstrated by significant deviations from Hardy-Weinberg allele frequencies; however this mutation was not associated with mosquito survival following insecticide exposure. A synergistic relationship between the L1014F $k d r$ and N1575Y mutations has been established in other parts of West Africa, where it has been shown to enhance resistance to pyrethroids and DDT, and potentially compensate for fitness costs incurred by L1014F $k d r$ [16]. By comparison, in Maferinyah, Guinea, this mutation was present at similar frequencies to Faranah and directly implicated in phenotypic resistance to permethrin [20].

The ability of the synergist PBO to re-establish full or partial susceptibility to both permethrin and deltamethrin indicates that mixed-function oxidases (MFOs) play some role in the resistance reported. However, the expression of metabolic enzymes examined in this study (CYP6M2, CYP6P3, and GSTD3), while significantly upregulated in wild $A n$. gambiae s.s. compared to the susceptible G3 colony, did not statistically differ between our pyrethroid resistant and susceptible wild-caught mosquitoes. Further exploratory analyses of our wild populations are warranted to characterize additional metabolic resistance pathways. Given the influence of MFOs as a predominant resistance mechanism to pyrethroids in the area and recent findings of improved protection with permethrin and PBO impregnated nets [25], the Guinea NMCP should consider including these next-generation nets in future vector control activities.

The G119S Ace-1 mutation, which confers resistance to carbamate and organophosphate insecticides [17] was found in this study to be highly predictive of bioassay survival to bendiocarb. Furthermore, CYP6P3 was significantly overexpressed in bendiocarb survivors, suggesting it may also be responsible for decreased susceptibility to carbamates in Faranah. Similar results implicating a role for $C Y P 6 P 3$ in bendiocarb metabolism and resistance have been reported from Côte d'Ivoire [26] and overexpression of this CYP450 has been documented among many multi-insecticide resistant field populations [5, $27-30]$.

In this study, mosquitoes that were reared from larvae collected from sites in the town of Faranah showed a higher mortality rate to permethrin at $1 \times$ and $2 \times$ the diagnostic dose, when compared to the wild-caught adult population of varying physiological age. This finding contradicts previous studies which have suggested that field-collected adults have higher mortality rates due to the mixture of ages and blood-feeding statuses in these populations [31], and the reported decline of phenotypic resistance with increasing mosquito age [32]. This observation strengthens the importance of utilizing the same methods of mosquito collection and assay preparation when testing field-collected mosquitoes [31] and cautions against the use of such data interchangeably. Because mosquito availability was a limiting factor, testing priority for replicates was given to insecticides where initial resistance was observed to the diagnostic dose, to more accurately characterize levels of phenotypic resistance intensity. Additional bioassay testing of larger samples sizes is required to corroborate these results in Faranah.

Malaria prevalence in Faranah Prefecture is approximately $15 \%$, reaching up to $25 \%$ [8]; mosquito infection rates in this study were $7.3 \%$. Because whole mosquito bodies were screened for P. falciparum by PCR, it is also possible that, in addition to infection or infectivity, a positive sample could be indicative of a mosquito which recently fed upon an infected human blood meal. More importantly, insecticide susceptible vectors were more likely to be infected with $P$. falciparum, but this phenomenon could not be ascribed to a single insecticide or resistance mechanism.

Additional considerations for the interpretation of study data include that in the tested population of $A n$. gambiae s.l., An. gambiae s.s. was the predominant species at $97.1 \%$, with An. coluzzii representing $1.3 \%$, and the hybrid form $1.3 \%$. Only two samples failed to produce any result on the An. gambiae complex end-point PCR assay. Anopheles gambiae s.s. breed in temporary, rain-dependent breeding sites [33], which could account for its predominance during the rainy season. Future collections at multiple timepoints, utilizing different collection methods would be necessary to determine the principal species in the area. Regarding sampling methodology, in this study mosquitoes were primarily collected using HLCs as this is often the most efficient technique to obtain large catches for bioassay testing. Due to heavy rains in the areas, larval breeding sites can be completely washed away, rendering this sampling method unpredictable. HLCs were chosen in favour of aspirating indoor resting, blood-fed adults and forcing oviposition, to generate an $F_{1}$ population, because house collections frequently yield low numbers of mosquitoes, potentially introducing family effects as a bias. In addition, preference was given to testing mosquitoes caught in HLCs, because the latter two techniques are not appropriate for pathogen screening. Finally, sampling took place in only three villages in one area of Guinea and, therefore, these findings cannot be extrapolated across the entire country. However, this information will contribute to an understanding of resistance in this region, which will be valuable information for the NMCP [34]. 


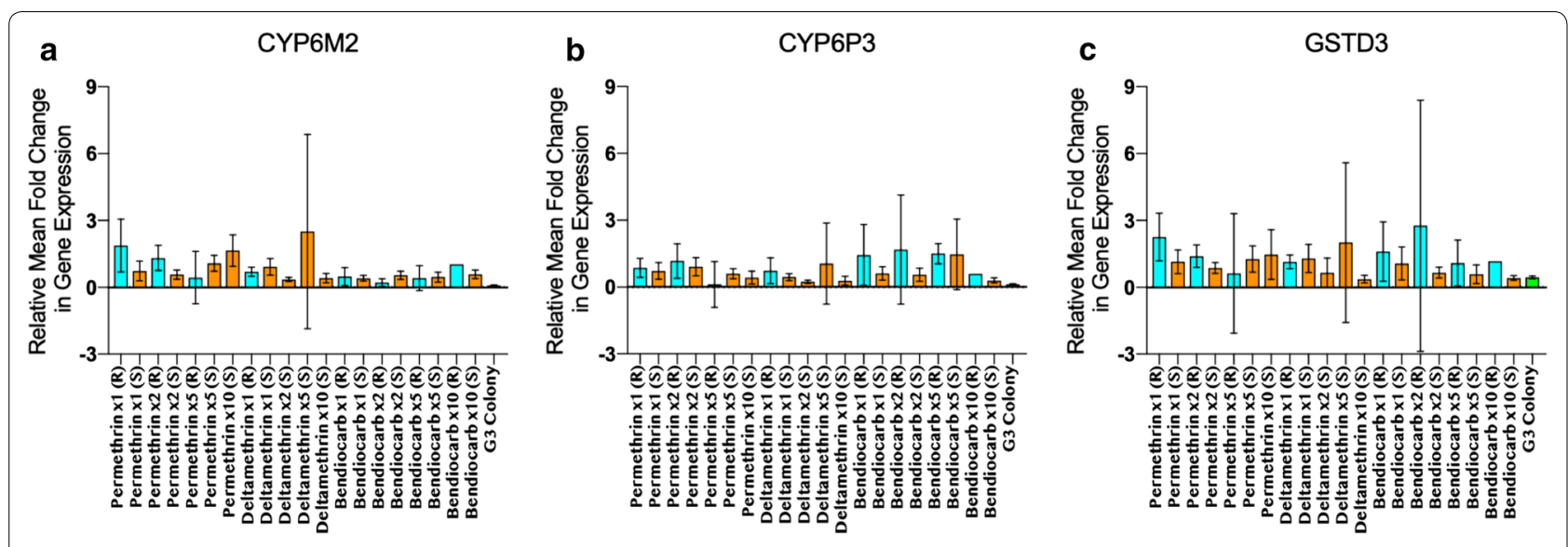

Fig. 3 Relative expression of genes (CYP6M2, CYP6P3, and GSTD3) and associated 95\% confidence intervals, for three insecticides that showed resistance at varying concentrations, normalized to the housekeeping gene RPS7 in An. gambiae s.s. populations in Faranah Prefecture and in the An. gambiae s.s. susceptible G3 colony. (R): resistant or alive; (S): susceptible or dead

\section{Conclusions}

Resistance to the pyrethroids, permethrin and deltamethrin, as well as possible resistance to bendiocarb were observed in Faranah Prefecture in Guinea. Both target site mutations (L1014F $k d r$, N1575Y and G119S Ace-1) and metabolic mechanisms of resistance are present in this field population. The complete susceptibility of vectors to alpha-cypermethrin, clothianidin, chlorfenapyr, and pirimiphos-methyl is encouraging, and these insecticides should be considered by the NMCP in future control efforts in the form of new LLIN and IRS interventions as they become approved and readily available.

\begin{abstract}
Abbreviations
Ace-1: acetylcholinesterase; Cox-1: cytochrome c oxidase subunit 1; CDC: Centers for Disease Control and Prevention; $\mathrm{Cl}$ : confidence interval; CNERS: Comité National d'Ethique pour la Recherche en Santé; CYP450: cytochromedependent monooxygenase 450; DDT: dichlorodiphenyltrichloroethane; GST: glutathione-s-transferase; HLC: human landing catch; IRB: institutional review board; IRS: indoor residual spraying; ITN: insecticide-treated net; $k d r$ : knockdown resistance; LLIN: long-lasting insecticidal net; LSHTM: London School of Hygiene and Tropical Medicine; MFO: mixed-function oxidase; NMCP: National Malaria Control Programme; PBO: piperonyl butoxide; PMI: President's Malaria Initiative; qRT-PCR: quantitative reverse transcriptase PCR; RPS7: ribosomal protein S7; WHO: World Health Organization.
\end{abstract}

\section{Acknowledgements}

The authors would like to thank all mosquito collectors for their dedicated work.

\section{Disclaimer}

The findings and conclusions in this report are those of the author(s) and do not necessarily represent the official position of the Centers for Disease Control and Prevention.

\section{Authors' contributions}

LAM, CS, SRI, CLJ and TW designed the study and were responsible for data analysis and interpretation. CS, YB, DC, IY and MK led the entomology field activities and participated in data collection. TW, CS and CLJ performed the molecular assays. CS, LAM, TW and SRI drafted the manuscript, which was revised by co-authors. All authors read and approved the final manuscript.

\section{Funding}

The authors would like to thank multiple partners for their financial support. Study funding was provided by a Bayer Research and Travel Grant for Vector Control and a London School of Hygiene and Tropical Medicine MSc Trust Fund Grant, both awarded to CS, and a Sir Halley Stewart Trust grant, awarded to LAM. CL and TW were supported by a Wellcome Trust/Royal Society Sir Henry Dale Fellowship awarded to TW (101285/Z/13/Z). LAM is supported by an American Society for Microbiology/Centers for Disease Control and Prevention Fellowship. SRI is supported by the President's Malaria Initiative $(\mathrm{PMI}) / \mathrm{CDC}$.

\section{Availability of data and materials}

Not applicable.

\section{Ethics approval and consent to participate}

The study protocol was reviewed and approved by the Comité National d'Ethique pour la Recherche en Santé (030/CNERS/17) and the institutional review boards (IRB) of the London School of Hygiene and Tropical Medicine (\#14990). The protocol was reviewed at the Centers for Disease Control and Prevention, USA and determined to be non-human subject research (reference number 2018-086); all study procedures were performed in accordance with relevant guidelines and regulations. Fieldworkers participating in human landing catches were provided with malaria prophylaxis for the duration of the study.

\section{Consent for publication}

Not applicable.

\section{Competing interests}

The authors declare that they have no competing interests.
Author details
${ }_{1}^{1}$ Department of Disease Control, Faculty of Infectious Tropical Diseases, London School of Hygiene and Tropical Medicine, London, UK. ${ }^{2}$ Entomology Branch, Division of Parasitic Diseases and Malaria, Center for Global Health, Centers for Disease Control and Prevention, Atlanta, GA, USA. ${ }^{3}$ Division of Parasitic Diseases and Malaria, President's Malaria Initiative, Center for Global Health, Centers for Disease Control and Prevention, Atlanta, GA, USA. ${ }^{4}$ Pro- gramme National de Lutte Contre le Paludisme, Ministère de la Santé, BP. 595, Conakry, Guinea. ${ }^{5}$ RTI International, Conakry, Guinea. ${ }^{6}$ American Society for Microbiology, 1752 N Street NW, Washington, DC 20036, USA. 
Received: 17 April 2019 Accepted: 8 July 2019

Published online: 17 July 2019

\section{References}

1. WHO. World malaria report 2018. Geneva: World Health Organization; 2018. https://apps.who.int/iris/bitstream/handle/10665/275867/97892 41565653-eng.pdf?ua=1. Accessed 5 Aug 2018.

2. Mnzava AP, Knox TB, Temu EA, Trett A, Fornadel C, Hemingway J, et al. Implementation of the global plan for insecticide resistance management in malaria vectors: progress, challenges and the way forward. Malar J. 2015;14:173.

3. Strode C, Donegan S, Garner P, Enayati AA, Hemingway J. The impact of pyrethroid resistance on the efficacy of insecticide-treated bed nets against African anopheline mosquitoes: systematic review and metaanalysis. PLoS Med. 2014;11:e1001619.

4. WHO. Global Malaria Programme. Malaria entomology and vector control: guide for participants. Geneva: World Health Organization; 2013. http://apps.who.int/iris/bitstream/handle/10665/85890/9789241505 819_eng.pdf; jsessionid=499D39C26B9EE5E5E260FF9D10DD6492? seque nce $=1$. Accessed 5 Aug 2018.

5. Djouaka RF, Bakare AA, Coulibaly ON, Akogbeto MC, Ranson H, Hemingway J, et al. Expression of the cytochrome P450s, CYP6P3 and CYP6M2 are significantly elevated in multiple pyrethroid resistant populations of Anopheles gambiae s.s. from Southern Benin and Nigeria. BMC Genomics. 2008;9:538.

6. Camara S, Koffi AA, Ahoua Alou LP, Koffi K, Kabran JK, Koné A, et al. Mapping insecticide resistance in Anopheles gambiae (s.l.) from Côte d'Ivoire. Parasit Vectors. 2018;11:19.

7. The Demographic and Health Surveys Program. Guinée: enquête démographique et de santé et à indicateurs multiples. 2012. https:// dhsprogram.com/pubs/pdf/FR280/FR280.pdf. Accessed 5 Aug 2018.

8. StopPalu President's Malaria Initiative Program Component. Annual report of entomological monitoring activities (November 2016-October 2017). 2017.

9. President's Malaria Initiative Guinea. Malaria operational plan fiscal year 2018; 2018. https://www.pmi.gov/docs/default-source/default-docum ent-library/malaria-operational-plans/fy-2018/fy-2018-guinea-malar ia-operational-plan.pdf?sfvrsn=5. Accessed 5 Aug 2018.

10. Keita K, Camara D, Barry Y, Osse R, Wang L, Sylla M, et al. Species identification and resistance status of Anopheles gambiae s.l. (Diptera: Culcidae) mosquitoes in Guinea. J Med Entomol. 2017;54:677-81.

11. Centers for Disease Control and Prevention. Guidelines for evaluating insecticide resistance in vectors using the CDC bottle bioassay. https ://www.cdc.gov/malaria/resources/pdf/fsp/ir_manual/ir_cdc_bioas say_en.pdf. Accessed 5 Aug 2018.

12. Santolamazza F, Mancini E, Simard F, Qi Y, Tu Z, della Torre A. Insertion polymorphisms of SINE200 retrotransposons within speciation islands of Anopheles gambiae molecular forms. Malar J. 2008;7:163.

13. Boissière A, Gimonneau G, Tchioffo MT, Abate L, Bayibeki A, AwonoAmbéné $\mathrm{PH}$, et al. Application of a qPCR assay in the investigation of susceptibility to malaria infection of the $\mathrm{M}$ and $\mathrm{S}$ molecular forms of $A n$. gambiae s.s. in Cameroon. PLoS ONE. 2013;8:e54820.

14. Coulibaly B, Kone R, Barry MS, Emerson B, Coulibaly MB, Niare O, et al. Malaria vector populations across ecological zones in Guinea Conakry and Mali, West Africa. Malar J. 2016;15:191.

15. MR4. Methods in Anopheles research. 2nd ed. 2016. https://www.beire sources.org/Portals/2NectorResources/2016\%20Methods\%20in\%20Ano pheles\%20Research\%20full\%20manual.pdf. Accessed 5 Aug 2018.

16. Jones CM, Liyanapathirana M, Agossa FR, Weetman D, Ranson H, Donnelly MJ, et al. Footprints of positive selection associated with a mutation (N1575Y) in the voltage-gated sodium channel of Anopheles gambiae. Proc Natl Acad Sci USA. 2012;109:6614-9.

17. Weill M, Malcolm C, Chandre F, Mogensen K, Berthomieu A, Marquine M, Raymond $M$. The unique mutation in ace-1 giving high insecticide resistance is easily detectable in mosquito vectors. Insect Mol Biol. 2004;13:1-7.

18. Yahouédo GA, Cornelie S, Djègbè I, Ahlonsou J, Aboubakar S, Soares C, et al. Dynamics of pyrethroid resistance in malaria vectors in southern Benin following a large-scale implementation of vector control interventions. Parasit Vectors. 2016;9:385.
19. Riveron JM, Watsenga F, Irving H, Irish SR, Wondji CS. High Plasmodium infection rate and reduced bed net efficacy in multiple insecticide-resistant malaria vectors in Kinshasa, Democratic Republic of Congo. J Infect Dis. 2018;217:320-8.

20. Collins E, Vaselli NM, Sylla M, Beavogui AH, Orsborne J, Lawrence G, et al. The relationship between insecticide resistance, mosquito age and malaria prevalence in Anopheles gambiae s.l. from Guinea. Sci Rep. 2019;9(1):8846.

21. Reimer L, Fondjo E, Patchoke S, Diallo B, Lee Y, Ng A, Ndjemai HM, Atangana J, Traore SF, Lanzaro G, Cornel AJ. Relationship between kdr mutation and resistance to pyrethroid and DDT insecticides in natural populations of Anopheles gambiae. J Med Entomol. 2008;45(2):260-6.

22. Ndiath MO, Cailleau A, Orlandi-Pradines E, Bessell P, Pages F, Trape JF, et al. Emerging knock-down resistance in Anopheles arabiensis populations of Dakar, Senegal: first evidence of a high prevalence of kdr-e mutation in West African urban area. Malar J. 2015;14:364.

23. Lekweiry KM, Salem MS, Cotteaux-Lautard C, Jarjaval F, Marin-Jauffre A, Bogreau $\mathrm{H}$, et al. Circumsporozoite protein rates, blood-feeding pattern and frequency of knockdown resistance mutations in Anopheles spp. in two ecological zones of Mauritania. Parasit Vectors. 2016;9:268.

24. Djegbe I, Akoton R, Tchigossou G, Ahadji-Dabla KM, Atoyebi SM, Adeoti R, et al. First report of the presence of L1014S knockdown-resistance mutation in Anopheles gambiae s.s. and Anopheles coluzzii from Togo, West Africa. Wellcome Open Res. 2018;3:30.

25. Protopopoff N, Mosha JF, Lukole E, Charlwood JD, Wright A, Mwalimu $C D$, et al. Effectiveness of a long-lasting piperonyl butoxide-treated insecticidal net and indoor residual spray interventions, separately and together, against malaria transmitted by pyrethroid-resistant mosquitoes: a cluster, randomised controlled, two-by-two factorial design trial. Lancet. 2018;391:1577-88.

26. Edi CV, Djogbenou L, Jenkins AM, Regna K, Muskavitch MA, Poupardin $R$, et al. CYP6 P450 enzymes and ACE-1 duplication produce extreme and multiple insecticide resistance in the malaria mosquito Anopheles gambiae. PLoS Genet. 2014;10:e1004236.

27. Kwiatkowska RM, Platt N, Poupardin R, Irving H, Dabire RK, Mitchell S, et al. Dissecting the mechanisms responsible for the multiple insecticide resistance phenotype in Anopheles gambiae s.s., M form, from Vallée du Kou, Burkina Faso. Gene. 2013;519:98-106.

28. Muller P, Warr E, Stevenson BJ, Pignatelli PM, Morgan JC, Steven A, et al. Field-caught permethrin-resistant Anopheles gambiae overexpress CYP6P3, a P450 that metabolises pyrethroids. PLoS Genet. 2008;4:e1000286.

29. Ngufor C, N'Guessan R, Fagbohoun J, Subramaniam K, Odjo A, Fongnikin A, et al. Insecticide resistance profile of Anopheles gambiae from a phase Il field station in Cové, southern Benin: implications for the evaluation of novel vector control products. Malar J. 2015;14:464.

30. Abdalla H, Wilding CS, Nardini L, Pignatelli P, Koekemoer LL, Ranson H, et al. Insecticide resistance in Anopheles arabiensis in Sudan: temporal trends and underlying mechanisms. Parasit Vectors. 2014;7:213.

31. Xu T, Zhong D, Tang L, Chang X, Fu F, Yan G, et al. Anopheles sinensis mosquito insecticide resistance: comparison of three mosquito sample collection and preparation methods and mosquito age in resistance measurements. Parasit Vectors. 2014;7:54.

32. Jones CM, Sanou A, Guelbeogo WM, Sagnon N, Johnson PC, Ranson $H$. Aging partially restores the efficacy of malaria vector control in insecticide-resistant populations of Anopheles gambiae s.l. from Burkina Faso. Malar J. 2012;11:24.

33. Zoh DD, Ahoua Alou LP, Toure M, Pennetier C, Camara S, Traore DF, et al. The current insecticide resistance status of Anopheles gambiae (s.I.) (Culicidae) in rural and urban areas of Bouaké, Côte d'Ivoire. Parasit Vectors. 2018;11:118.

34. Ranson H, Abdallah H, Badolo A, Guelbeogo WM, Kerah-Hinzoumbé C, Yangalbé-Kalnoné E, et al. Insecticide resistance in Anopheles gambiae: data from the first year of a multi-country study highlight the extent of the problem. Malar J. 2009;8:299.

\section{Publisher's Note}

Springer Nature remains neutral with regard to jurisdictional claims in published maps and institutional affiliations. 